\title{
Fournier's Gangrene: Approaches to the Diagnosis and Treatment
}

\author{
Md. Ashrafuzzaman ${ }^{1}$, Avisak Bhattacharjee ${ }^{2}$, Mahbubur Rahman ${ }^{3}$
}

\begin{abstract}
Background: Fournier's gangrene is a rare, rapidly progressive, necrotizing fasciitis of the external genitalia and perineum. Objective: The main aim of this study was to observe comprehensively the disease profile of Fournier's gangrene, with a specific intent to observe the proportion of patient presenting with Fournier's gangrene. Materials and method: This cross sectional study was done in Sir Salimullah Medical College \& Mitford Hospital, Dhaka, Bangladesh. By purposive sampling from the admitted patients of department of Surgery 22 patients were finalized according to the eligibility criteria. Patients were thoroughly evaluated and managed and all relevant data were recorded. Data were managed, edited and plotted in tabular and figure form. Data analysis was done by chi square test. $p$ value was significant at $<0.05$. Results: The mean $\pm S D$ age of the patients was $43.9 \pm 14.82$ years. Among the study subjects $68.2 \%$ showed insidious onset whereas remaining showed abrupt onset. Both cutaneous and anorectal factors claimed the highest (36.4\%) of etiology. Pain and Oedema were the prime manifestation. In 59\% cases testes were not exposed. In $36.4 \%$ cases only scrotum was involved whereas in $22.7 \%$ cases both scrotum and perineum were involved. After provision of aggressive treatment in $72.7 \%$ cases no complication was observed. During treatment 9.1\% subjects expired. Conclusion: Elderly and low economic profile people are frequently affected with Fournier's gangrene. To reduce the significant morbidity and mortality aggressive medical and surgical management is mandatory.
\end{abstract}

Keywords: Fournier's gangrene; necrotizing fasciitis; external genitalia.

Delta Med Col J. Jul 2017;5(2):68 - 75

\section{Introduction}

Fournier's gangrene is a variety of necrotizing fasciitis of the genital, perianal and perineal regions which may extend up to abdominal wall between the fascial planes; it is a rare disease which expresses as rapidly progressive and fulminant form. ${ }^{1}$ A French dermatologist and venerologist named Professor Jean Alfred Fournier (1832-1914) first described this clinically devastating condition in $1883 .^{2}$ He basically described a syndrome of unexplained gangrene in the penis and scrotum in 5 young men with no other pathologic basis of sudden onset and rapid progression. ${ }^{3}$

1. Senior Consultant, District Hospital, Rajbari, Bangladesh.

2. Assistant Registrar, Dept. of Surgical Oncology, Mohakhali, Dhaka, Bangladesh.

3. Assistant Professor, Dept.of Surgery, Mughda Medical College, Dhaka, Bangladesh.

Correspondence: Dr. Avisak Bhattacharjee. e-mail: abhishakdr123@gmail.com 
The basic pathology of mother entity of Fournier's gangrene, necrotizing fasciitis is the damage of subcutaneous fat layer (containing nerve and vascular structures) as well as the superficial and deep fascia layers. Hippocrates first mentioned necrotizing fasciitis in 500 B.C. as a complication of 'erysipelas', an acute and often recurring bacterial infections. ${ }^{4}$ The disease is characterized by on obliterative end arteritis of small blood vessels of the subcutaneous tissue secondary to polymicrobial infection acting synergistically to allow rapid invasion and tissue necrosis. ${ }^{1}$

The precise etiology of the disease remains still unclear. Initially Fournier's gangrene was defined as on idiopathic entity, but now-a-days, it is recognized that this disease is due to either perineal or genital skin infections. Anorectal or urogenital and perineal trauma, including pelvic and perineal injury or pelvic interventions are other causes of Fournier's gangrene. ${ }^{5}$ Diabetes mellitus and chronic alcoholism are responsible for $20 \%-70 \%$ and $25 \%-50 \%$ patients respectively. 6

The clinical features and relevant investigations are the mainstay of diagnosis of the disease. This gangrene apparently shows vast heterogeneity in clinical presentation from insidious onset and slow progression to rapid onset and fulminant course, the latter being the more common presentation. ${ }^{7}$ The infection commonly starts as cellulites adjacent to the portal of entry, depending on the source of infection, commonly in the perineum or perianal region. Locally significant pain and swelling with crepitus are common features. ${ }^{8}$

Necrotic patches start to appear on overlying skin and progress to extensive necrosis if subcutaneous inflammation worsens. Sepsis and multi organ failure are the common causes of death in these patients if not aggressively treated. So systemic manifestation is also a deteriorating sign of Fournier's gangrene. Laor et al. developed a scoring system (Fournier's gangrene severity index or FGSI), to quantify the severity of infection, using common vital sign and laboratory data. ${ }^{7}$ This score helps to predict the mortality. The patients having score of $>9$ have $75 \%$ mortality chance while the patients having score of $<9$ have $78 \%$ probability of survival. Chawla et al. rightly marked the limitation of this scoring that it can't predict the length of hospital stay. ${ }^{9}$

Fournier's gangrene has a long list of differential diagnoses. Investigations are aimed to identify the cause and concomitant diseases to enable effective treatment. The treatment consists of urgent resuscitation, use of broad spectrum parenteral antibiotics, aggressive surgical debridement, tetanus prophylaxis and supportive care followed by subsequent reconstruction of the residual defect. ${ }^{10}$ Despite modern intensive care unit (ICU) management the mortality rate of Fournier's gangrene remains high $(3-67 \%) .{ }^{11}$

In Bangladesh, we encounter a good number of patients in our hospitals. There is no previous study on this relatively rare but serious clinical entity in our country. So, it will be appropriate to make an effort on this ground in our perspective. This present study aimed to observe comprehensively the disease profile of Fournier's gangrene, with a specific intent to observe what proportion of patient presents with it.

\section{Materials and method}

This study was conducted in the department of Surgery of Sir Salimullah Medical College \& Mitford Hospital, Dhaka, Bangladesh from June 2008 to May 2009. This was a cross sectional observational study where the subjects were selected by the purposive sampling. Eligibility criteria include clinical features consistent with rapidly progressive fulminating infection arising primarily from the perianal, perineal and genital 
region and presence of necrotic tissue on surgical exploration.

The initial clinical evaluation of the patients was done by taking adequate history, proper physical examinations and some relevant investigations. A blood sample was collected to do the complete blood count, random plasma sugar, serum creatinine, serum albumin, $\mathrm{LDH}$, liver function test, electrolytes and culture, sensitivity. Thereafter, a wound swab was collected and sent for culture. A urine sample was collected and sent for routine and microscopic examination and culture.

Initial resuscitation was done with crystalloids or crystalloids and whole blood; as per requirement. Broad spectrum parenteral antibiotic was started on empirical basis. After resuscitation aggressive debridement of all dead tissues, followed by irrigation of the wound with hydrogen peroxide and normal saline. The wound was covered with EUSOL soaked gauge. Tissue was taken and sent for histopathological examination.

Urethral catheterization was done aseptically where needed. The wound was checked regularly. Regular dressing was done. In some cases repeated surgical debridement was needed. When healthy granulation tissue formed and the size of the wound reduced, resurfacing of the wound was done by the secondary suture technique and in some cases, partial thickness skin graft and local pedicle flap graft was done. The exposed testis was implanted in to the medial aspect of the thigh. From the admission physiological and laboratory parameters FGSI was calculated.

Before approaching for the study proper ethical clearance was taken from the Ethical Review Committee (ERC) of Sir Salimullah Medical College and Mitford Hospital, Dhaka, Bangladesh.

\section{Statistical analysis}

Data were collected by a pre-structured, peer reviewed case record form (CRF). Collected data were compiled and statistically analyzed by using computer based programmed statistical package for social science (SPSS) for windows version-12. Chi-square $\left(\mathrm{x}^{2}\right)$ test, Student's ' $\mathrm{t}$ ' test, were done to make inference. $p$-value $<0.05$ was considered as significant.

\section{Results}

A total of 22 cases of Fournier's gangrene were treated between June 2008 to May 2009. All the subjects were male. The mean $( \pm \mathrm{SD})$ age of the patients was $40.90 \quad( \pm 14.82)$ years. The mean $( \pm \mathrm{SD})$ body weight was $58.95( \pm 5.34) \mathrm{kg}$. The mean $( \pm \mathrm{SD})$ body temperature of the patients at hospital admission was $101.22( \pm 1.14)^{\circ} \mathrm{F}$ and mean $( \pm \mathrm{SD})$ delay between onset of the disease and hospital admission was $7.68( \pm 3.98)$ days. The mean $( \pm \mathrm{SD})$ duration of hospital stay was 31.86 $( \pm 0.90)$ days. Mean Fournier's gangrene severity index (FGSI) was $5.5( \pm 3.44)$ (Table I).

Table I: Distribution of studied variables $(\mathrm{N}=22)$

\begin{tabular}{lccc}
\hline Variables & Minimum & Maximum & Mean $( \pm$ SD) \\
\hline Age (Years) & 18 & 75 & $43.9( \pm 14.82)$ \\
Weight (Kg) & 48.00 & 70.00 & $58.59( \pm 5.35)$ \\
Temperature ( $\left.{ }^{\circ} \mathrm{F}\right)$ & 99.00 & 103.00 & $101.2( \pm 1.14)$ \\
Hospital Stay (days) & 5.00 & 77.00 & $31.86( \pm 23.48)$ \\
FGSI & 1.00 & 14.00 & $5.530( \pm 3.4)$ \\
Delay (days) & 2.00 & 15.00 & $7.68( \pm 3.98)$ \\
\hline
\end{tabular}

Out of total 22 patients $9(40.9 \%)$ were day labourer, 5 (22.7\%) were farmer, 4 (18.1\%) were service holder and rest 4 (18.1\%) belonged to others (Fig 1).

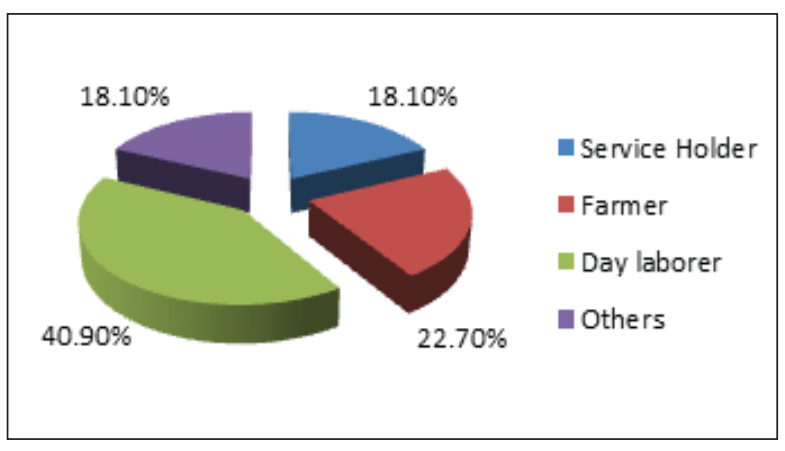

Fig 1: Occupation of the study population 
At the time of hospital admission, 15 (68.2\%) patients presented with an abrupt onset and 7 $(31.8 \%)$ cases presented with an insidious onset (Fig 2).

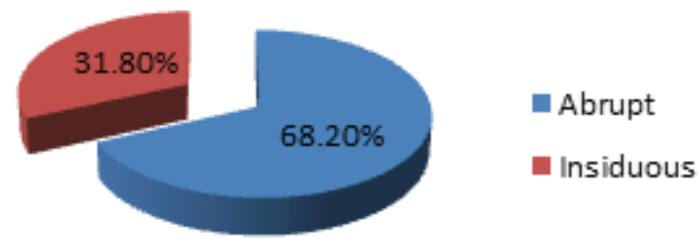

Fig 2: Pattern of onset of the disease

Though diabetes is a common predisposing factor development of Fournier's gangrene, only 4 $(18.2 \%)$ cases were diabetic. Among the subjects $10(45.5 \%)$ patients were from poor social class, 2 (9.1\%) gave history of alcohol intake and 1 (4.5\%) was associated with carcinoma rectum, 5 (22.7\%) cases no associated risk factor could be identified (Fig 3).

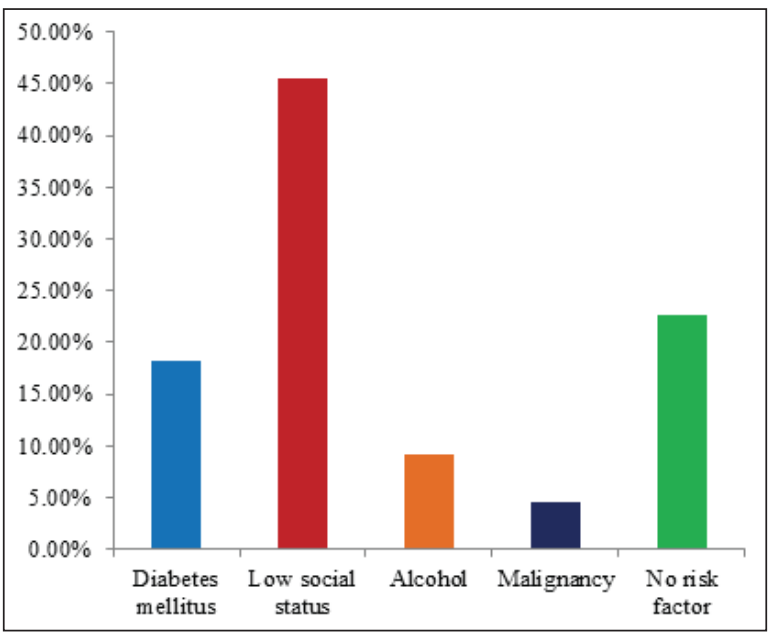

Fig 3: Distribution of the study subjects according to associated risk factors

Out of 22 cases, the underlined aetiological process could be identified in $19(86.4 \%)$ cases. The commonest cause was cutaneous (local skin sepsis) in $8(36.4 \%)$ and colorectal (Perianal abscess, haemorrhoids, fistula) In 8 (36.4\%) cases urinary tract lesions (Periurethral abscess, urethral stricture) in $2(9.1 \%)$ cases, post operative 1 $(4.5 \%)$ cases. No cause was found in $3(13.6 \%)$ cases (Table II).
Table II: Distribution of the study subjects according to Aetiology $(\mathrm{N}=\mathbf{2 2})$

\begin{tabular}{lcc}
\hline Aetiology & Frequency & Percentage \\
\hline Cutaneous & 8 & 36.4 \\
Anorectal & 8 & 36.4 \\
Postoperative & 1 & 4.5 \\
Urogenital & 2 & 9.1 \\
Unknown & 3 & 13.6 \\
\hline
\end{tabular}

On hospital admission, the testes were exposed after sloughing out of gangrenous tissue in 9 (40.9\%) cases and in $13(59 \%)$ cases testis was not exposed (Fig 4).

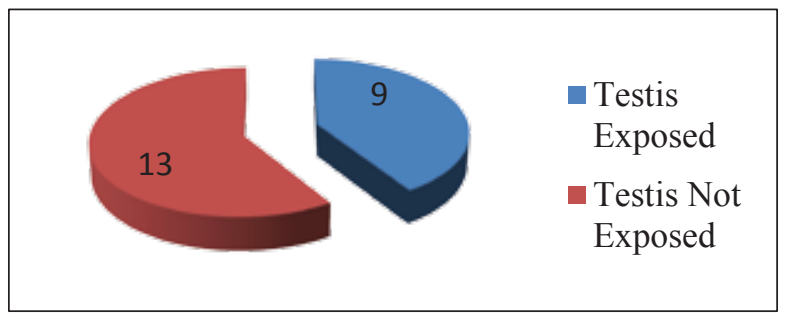

Fig 4: Exposure of testis

Among the presenting clinical features pain, Oedema, erythema, and scrotal skin necrosis was found in almost all the cases. There was fever in $86.36 \%$ cases, leukocytosis in $72.2 \%$ cases, dysuria in $45.5 \%$ cases, crepitus in $40.90 \%$ cases, shock in $38.3 \%$ cases and glycosuria in $18.2 \%$ cases. (Table III)

Table III: Clinical presentation of Fournier's Gangrene

\begin{tabular}{lcc}
\hline *Signs and smptoms & Frequency & Percentage \\
\hline Pain & 22 & 100 \\
Oedema & 22 & 100 \\
Fever & 19 & 86.36 \\
Erythema & 22 & 100 \\
Crepitus & 9 & 40.90 \\
Scrotal Skin necrosis & 22 & 100 \\
Glycosuria & 4 & 18.2 \\
Leukocytosis & 16 & 72.2 \\
Shock & 8 & 38.3 \\
Dysuria & 10 & 45.5 \\
\hline
\end{tabular}

*Multiple responses 
Area involved in the necrotic process had varied extension in to the surrounding tissues. Only Scrotum was involved in 8 (36.4\%) cases, scrotum and perineum in $5(22.7 \%)$ cases, scrotum and groin in $2(9.1 \%)$ cases, scrotum and anterior abdominal wall in $3(13.6 \%)$ cases and $1(4.5 \%)$ in each cases of scrotum and penis, scrotum and thigh, scrotum plus buttock, and scrotum, anterior abdominal wall plus thigh respectively (Table IV).

Table IV: Area involved in the necrotic process among the study subjects $(\mathrm{N}=22)$

\begin{tabular}{lcc}
\hline Area involved & Frequency & Percentage \\
\hline Scrotum & 8 & 36.4 \\
Scrotum +Groin & 2 & 9.1 \\
Scrotum + Anterior Abdominal wall & 3 & 13.6 \\
Scrotum+ Perineum & 5 & 22.7 \\
Scrotum+ penis & 1 & 4.5 \\
Scrotum+ Buttock & 1 & 4.5 \\
Scrotum + thing & 1 & 4.5 \\
Scrotum + Anterior Abdominal wall + thigh & 1 & 4.5 \\
\hline
\end{tabular}

Pus was taken from the wound of all the cases for culture and sensitivity and yielded growth of many types of organisms in varying combinations. The organisms were indigenous commensal below the pelvic diaphragm and genital tract. They included pseudomonas, streptococci, staphylococci, peptostreptococci. The most common organism isolated was E. coli in 15 (68.2\%) cases (Fig 5).

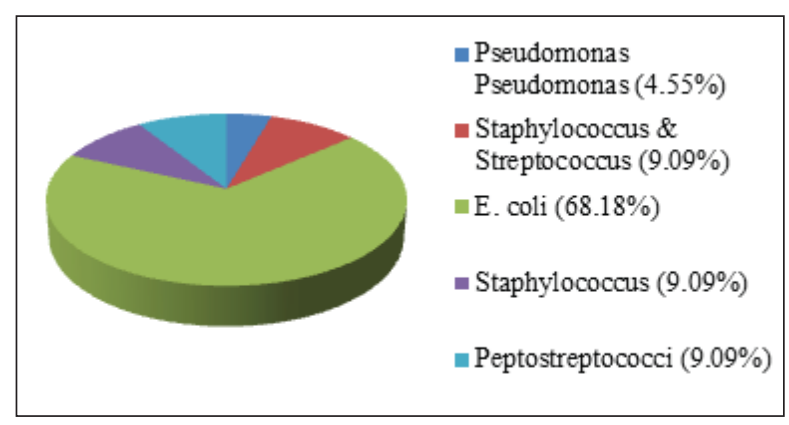

Fig 5: Organisms involved

Out of 22 cases $2(9.1 \%)$ patients died. One patient died of septicemia despite adequate resuscitation and wound debridement. The patient had concomitant renal failure, COPD, and carcinoma of rectum. Another patient developed ARDS followed by multiple organ failure (MOF) (Fig 6).
During treatment $3(13.6 \%)$ patients developed ARDS and $1(4.5 \%)$ patient developed septicemia, another $1(4.5 \%)$ case developed CRF with cardiac arrest (Table V).

Table V: Complications developed during treatment of study subjects $(\mathrm{N}=22)$

\begin{tabular}{lcc}
\hline Complication & Frequency & Percentage \\
\hline No complication & 16 & 72.7 \\
Developed ARDS & 3 & 13.6 \\
Septicemia & 1 & 4.5 \\
CRF+ Cardiac Arrest & 1 & 4.5 \\
Respiratory tract infection & 1 & 4.5 \\
\hline
\end{tabular}

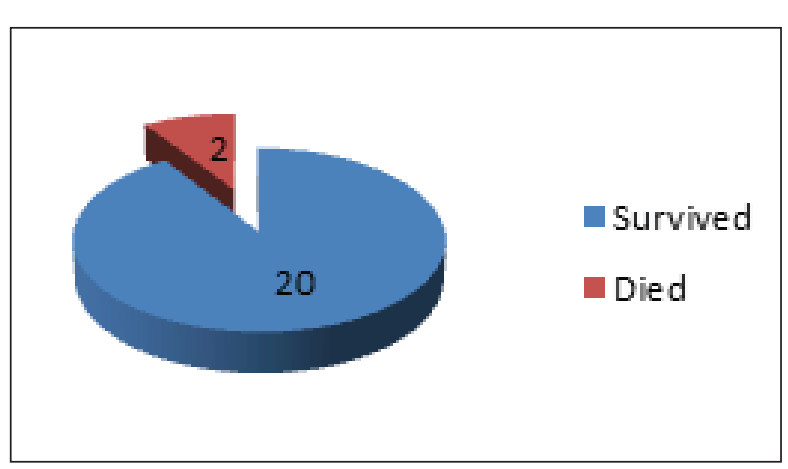

Fig 6: Outcome of treatment among the study subjects

The table VI shows the comparison of survived and died patients according to delay of hospital admission. Mean $( \pm \mathrm{SD})$ delay of survived patients was $7.50( \pm 4.05)$ days and mean $( \pm \mathrm{SD})$ delay of died patients was $9.50( \pm 3.53)$ days. Statistical analysis with t-test showed significant difference $(\mathrm{t}=0.733, \mathrm{p}=<0.001)$.

Table VI: Comparison between delay of hospital admission and final outcome $(\mathrm{N}=22)$

\begin{tabular}{llll}
\hline Outcome & $\begin{array}{c}\text { Delay (days) } \\
\text { Mean } \pm \text { SD }\end{array}$ & t-value & p-value \\
\hline Survived(n=20) & $7.50 \pm 4.058$ & 0.733 & $<0.001^{\mathrm{S}}$ \\
Died (n=2) & $9.50 \pm 3.53$ & & \\
\hline
\end{tabular}

S: Significant

The table VII \& VIII show the comparison and association between survived and died patients with FGSI score. Pearson Chi square $\left(\mathrm{x}^{2}\right.$ test showed significant association $\left(\mathrm{x}^{2}=5.86\right.$, $\mathrm{p}=0.035$ ). 
Table VII: FGSI with final outcome $(\mathrm{N}=\mathbf{2 2})$

\begin{tabular}{lccc}
\hline Outcome & FGSI & t-value & p-value \\
& Mean \pm SD & & \\
\hline Survived (n=20) & $6.95 \pm 3.72$ & 2.24 & $0.037^{\mathrm{S}}$ \\
Died (n=2) & $13.00 \pm 1.41$ & & \\
\hline
\end{tabular}

S: Significant

Table VIII: Association of FGSI with final outcome $(\mathrm{N}=22)$

\begin{tabular}{lcccc}
\hline FGSI & \multicolumn{2}{c}{ Outcome } & $X^{2}$ & p value \\
& Survived (n=20) & Died (n=2) & & \\
\hline $\mathbf{1 - 5}$ & $9(100 \%)$ & $0(0 \%)$ & & \\
$\mathbf{6 - 1 0}$ & $7(100 \%)$ & $0(0 \%)$ & 5.86 & $0.035 \mathrm{~s}$ \\
$>\mathbf{1 0}$ & $4(66.7 \%)$ & $2(33.3 \%)$ & & \\
\hline
\end{tabular}

S: Significant

\section{Discussion}

Fournier's gangrene is a necrotizing fasciitis of soft tissues of the scrotum and perineum of very rapid evolution. The patients with Fournier's gangrene usually have concomitant risk factors. ${ }^{3}$ Since the initial reports, Fournier's gangrene has come to involve an older group of population and is known to be an infectious process with an identifiable source in $95 \%$ cases. $^{12}$ It is not very much common from the point of view of surgical audit. During the study period a total number of 8419 patient were admitted. Out of 8419 patients, $22(0.26 \%)$ patients presented with Fournier's gangrene. The mean age of the patients was 43.90 $( \pm 14.82)$ years. The most of the patients were from 41-50 years age group. The average age in most published series varies from 40.9 to 61.7 years that agrees with the finding of our study. ${ }^{13}$ Sorensen et al. ${ }^{14}$ in a population based study of 1641 cases, showed that age was a strong predictor of mortality. However Tuncel et al. ${ }^{15}$ and Corcocan et al. ${ }^{16}$ did not find any significant age differences between survivors and non survivors.

Clayton and co workers ${ }^{17}$ showed that the urogenital is the commonest source of infection followed by anorectal foci and cutaneous source. ${ }^{17}$ Our study also found similar findings. The common urogenital causes include urethral strictures and indwelling catheter in multiple studies. ${ }^{1}$ Similar findings were also found in our study. Far from idiopathic, a source of infection could be identified in $86.4 \%$ cases and no cause was found in $13.6 \%$ cases. In a Spanish study by Marco et al. ${ }^{18} 40 \%$ of the cases were of idiopathic origin, they acknowledged that the source of infection might have been overlooked in the process. In this series of patients with urogenital source of infection, urethral stricture disease was observed as well as indwelling catheters. Poor catheter care was the prime suspect here.

The disease occurs in affluent as well as in the poor community. ${ }^{19}$ Most of the patients usually present with a delay of 2-7 days from the onset of the disease. ${ }^{20} 45.5 \%$ patients were from lower socioeconomic class. Financial condition is a common cause of delayed presentation. Certain conditions like diabetes mellitus, obesity, alcohol intake, low socioeconomic status, malignancy, HIV, cirrhosis, vascular diseases, etc are frequently associated with Fournier's gangrene. ${ }^{12}$ In this study $18.2 \%$ patients found diabetic and there was history of alcohol intake in $9.1 \%$ cases. One patient suffered from carcinoma rectum and 10 (45.5\%) patients were from poor social class.

The multiplicity of organisms isolated from cases of Fournier's gangrene suggests that, none of them could be properly regarded as the cause of the disease. The organisms are commensals below the pelvic diaphragm and they are opportunistic in addition to their synergistic activity. Such infections are secondary complication of primary ischemic process. ${ }^{19}$ Many types of organisms in varying combination were isolated from culture of pus taken from the wound, such as E coli. streptococci, staphylococci, pseudomonas and peptostreptococci. E coli were the most common organism isolated in 15 (68.2\%) cases. To assess, the better physiological profile of the patients in both outcome categories, the APACHE-II severity score was modified to create Fournier's gangrene severity index (FGSI). The mean $( \pm \mathrm{SD})$ FGSI for 
survivors was $6.9( \pm 0.9)$ compared to $13.5( \pm 1.5)$ for nonsurvivors. ${ }^{7}$

On admission clinical and laboratory parameters were recorded and the Fournier's gangrene severity index (FGSI) was calculated. This study revealed that initial evaluation of FGSI have got importance. The FGSI was compared to final outcome (survived and died patients) showed statistically significant difference.

Early diagnosis, prompt and aggressive management is the most important aspect of treatment of Fournier's gangrene. Clinical differentiation of necrotizing fasciitis from cellulitis may be difficult because initial signs including pain, oedema, erythema are not distinctive. However, presence of marked toxicity out of proportion to the local findings should alert the clinicians about rapid haemodynamic resuscitation. Antimicrobial treatment with broad spectrum combinations followed by prompt and aggressive surgical debridement along with treatment of the predisposing causes is the recommended management of Fournier's gangrene.

The observation of the present study supports the above comments. Rapid haemodynamic resuscitation was done with $\mathrm{I} / \mathrm{V}$ fluid and/or blood followed by administration of combined parenteral antibiotic. Prompt and aggressive surgical debridement was done. A mean $( \pm \mathrm{SD})$ of $1.63( \pm 0.90)$ number of debridement was done. The number of debridement was compared with final outcome (survived and died) which showed significant difference. Resurfacing of the residual defect was done using secondary suturing technique, partial thickness skin grafting and local pedicle flap coverage. None of the 22 patients gave history of immunization. Tetanus prophylaxis was done routinely.

The mortality rate varies from $0-67 \%$ in different studies. Contrary to the previous literature mortality rate was $9.1 \%$ ( 2 out of 22 cases). The mean $( \pm \mathrm{SD})$ duration of hospital stay was 31.86 $(0.90)$ days. The duration of stay at the hospital for
Fournier's gangrene ranged between 2-278 days in previous studies. ${ }^{21}$

This study also revealed that non survivors had a significantly larger body surface area involvement compared with survivors and that a body surface area of greater than $5 \%$ was significantly associated with poor outcome $(\mathrm{p}=0.004)$ (data not shown). This is similar to studies by Palmer et al. ${ }^{22}$ and Spinark et al. ${ }^{23}$ which showed that patients with a body surface area involvement of greater that $5 \%$ have a higher mortality. They noted that survival is not directly proportional to body surface area involvement. ${ }^{15}$ The extent of body surface area involvement would indicate severity of disease hence its association with mortality. This issue remains debatable as some authors dispute the association of body surface area involvement with poor outcome. ${ }^{16}$

A number of studies have shown the effectiveness of hyperbaric oxygen therapy, as it provides adequate oxygen for optimal neutrophil phagocytic function, inhibits anaerobic growth, increases fibroblast growth and angiogenesis, reduces oedema by vasoconstriction, increases intracellular transport of antibiotic and increases generation of oxygen free radicals. ${ }^{2}$ However, this technology was not available in our hospital and therefore could not be used.

In some centers, colostomy is routinely performed to prevent faecal contamination of the wound. ${ }^{24}$ None of the patient needed colostomy and did well regarding wound healing. Simple washing of the wound was all that was ensured after each defaecation.

\section{Conclusion}

Fournier's gangrene is not very much common still yet in our context. All the patients presented with the disease are elderly and from predominantly lower class. The prominent clinical features are pain, fever, scrotal erythema, and sloughing of the perineo-scrotal skin with foul smelling discharge. The basis of good management remains aggressive 
surgical debridement, broad spectrum parenteral antibiotics and intensive supportive care followed by resurfacing of residual defect either by secondary suturing or by skin grafting.

\section{References}

1. Corman JM, Moody JA, Aranson WL. Fournier's Gangrene in a Modern Surgical Setting: Improved Survival with Aggressive Management. Br J Urol Int. 1999;84:85-88.

2. Smith GL, Bunker CB, Dineeen MD. Fournier's Gangrene. Br J Urol. 1998;81:347-55.

3. Gómez JP, Prósper AV, Tortosa IR, Armada JRB, Lloret VC, de Laorden SJC. Gangrena de Fournier. Arch Esp Urol. 2006;59(8):767-71.

4. Descamps V, Aitken J, Lee MG. Hippocrates on Necrotising Fasciitis [letter]. Lancet. 1994;344:556.

5. Eke N. Fourniers Gangrene: A Review of 1726 Cases. Br J Surg. 2000;87:718-28.

6. Morpurgo E, Galandiuk S. Fournier's Gangrene. Surg Clin N Am. 2002;82:1213-24.

7. Laor E, Palmer TS, Tolia BM, Reid RE, Winter HI. Outcome Prediction in Patients with Fournier's Gangrene. J Urol. 1995;154:89-92.

8. Patty R, Smith AD. Gangrene and Fourniers Gangrene. Urol Clin North Am. 1992;19:149.

9. Chawla SN, Gallop C, Mydlo JH. Fournier's Gangrene: An Analysis of Repeated Surgical Debridement. Eur Urol. 2003;43:572-75.

10. Singh G, Chawla S. Aggressiveness - The Key to a Successful Outcome in Necrotising Soft Tisssue Infection. MJAFI. 2003;59:21-24.

11. Unalp HR, Kamer E, Derici H, Atahan K, Balci U, Demirdoven C, et al. Fournier's Gangrene: Evaluation of 68 Patients an Analysis of Prognostic Variables. J Postgrad Med. 2008;54:102-105.

12. Santora T, Rukstalis DB. Fournier Gangrene [Internet]. 2007 (cited 2016 May 31). Available from: http://www.emedicine.com/med/topic2814. $\mathrm{htm}(7 \mathrm{of} 19)$.

13. Samano VL, Ixquiac-Pineda G, Alcaraz EM, Montoya G, Brambila ES, Alarcon JP. Gangrena de
Fournier: Experiencia en Hospital de Especialidades del CMN SXXI. Arch Esp Urol. 2007;60(5):525-30.

14. Sorensen MD, Krieger JN, Rivara FP, Klien MB, Hunter W. Fournier's Gangrene: Population Based Epidemiology and Outcomes. J Urol. 2009;181:2120-26.

15. Tuncel A, Aydin O, Tekdogan U, Nalcacioglu V, Capar Y, Atan A. Fournier's Gangrene: Three Years of Experience with 20 Patients and Validity of the Fournier's Gangrene Severity Index Score. Eur Urol. 2006;50(4):838-43.

16. Corcoran AT, Smaldone MC, Gibbons EP, Walsh TJ, Davies BJ. Validation of the Fournier's Gangrene Severity Index in a Large Contemporary Series. J Urol. 2008;180:944-48.

17. Clayton MD, Fowler JE Jr, Sharifi R, Pearl RK. Causes, Presentation and Survival of Fifty Seven Patients with Necrotizing Fasciitis of the Male Genitalia. Surg Gynecol Obstet. 1990;170:49-55.

18. Marco SL, Budia A, di Capua C, Broseta E, Jiménez Cruz F. Evaluation of a Severity Score to Predict Prognosis of Fournier's Gangrene. BJU International. 2009;106:373-76.

19. Eke N. Fournier's Gangrene: A Review of 1726 Cases. Br J of Surg. 2000;87:718-28.

20. Paty R, Smith AD. Gangrene and Fournier's Gangrene. The Urol Clin of North Am. 1992;19:149-62.

21. Unal B, Kocer B, Ozel E, Boskurt B, Yildirim O, Altun B, et al. Fournier Gangrene Approaches to Diagnosis and Treatment. Saudi Med. 2006;27:1038-43.

22. Palmer LS, Winter HI, Tolia BM, Reid RE, Laor E. The Limited Impact of Involved Surface Area and Surgical Debridement on Survival in Fournier's Gangrene. British Journal of Urology. 1995;76:208-12.

23. Spinark JP, Resnick MI, Hampel N, Persky L. Fournier's Gangrene: Report of 20 Patients. J Urology. 1984;131:289-91.

24. Ayan F, Sunamak O, Paksoy SM, Polat SS, Sakoglu $\mathrm{N}$, Cetnkale O, et al. Fournier's Gangrene: A Retrospective Clinical Study on Forty-One Patients. ANZ Surg. 2005;75:1055-58. 